\title{
ConTROLE DE Brachiaria brizantha COM Uso do GLYPHOSATE APÓS O EstabeleCimento de TifTon 85 (Cynodon spp.) ${ }^{1}$
}

\author{
Control of Brachiaria brizantha with Glyphosate's After Tifton's 85 (Cynodon spp.) \\ Establishment
}

\author{
SANTOS, M.V. ${ }^{2}$, FERREIRA, F.A. ${ }^{3}$, FREITAS, F.C.L. ${ }^{4}$, TUFFI SANTOS, L.D. ${ }^{5}$ e \\ FONSECA, D.M. ${ }^{6}$
}

\begin{abstract}
RESUMO - A eficiência do glyphosate no controle de Brachiaria brizantha cv. Marandu em áreas de cultivo do Tifton 85 foi avaliada utilizando o delineamento experimental em blocos casualizados, com oito doses de glyphosate $\left(0,90,180,360,720,1.080,1.440\right.$ e $\left.1.800 \mathrm{~g} \mathrm{ha}^{-1}\right)$, e quatro repetições. Cada parcela foi constituída de um vaso com duas plantas de $B$. brizantha cv. Marandu e duas plantas de Tifton-85. A aplicação do herbicida foi feita quando as plantas de $B$. brizantha apresentavam cerca de $40 \mathrm{~cm}$ de altura. O nivel de intoxicação nas plantas de Tifton 85 e a eficiência do herbicida no controle de $B$. brizantha foram avaliados aos 15,30 e 60 dias após aplicação (DAA). Aos 60 DAA, as plantas foram colhidas ao nível do solo e secas em estufa. A rebrota foi avaliada, do mesmo modo, aos 60 dias após o corte (DAC). Obeservouse controle superior a $90 \%$ de $B$. brizantha, a partir da dose de 738,28 $\mathrm{g} \mathrm{ha}^{-1}$ de glyphosate, enquanto a intoxicação para as plantas de Tifton 85 foi de apenas 12,05. Aos 60 DAA, houve redução na produção de massa seca de braquiária a partir da dose de $90 \mathrm{~g} \mathrm{ha}^{-1}$. Doses superiores a $720 \mathrm{~g} \mathrm{ha}^{-1}$ diminuíram o crescimento e desenvolvimento do Tifton 85, afetando sua produção, sem, no entanto, ocasionar a morte das plantas. Os resultados evidenciam boa tolerância do Tifton 85 até a dose de $720 \mathrm{~g} \mathrm{ha}^{-1}$ de glyphosate.
\end{abstract}

Palavras-chave: braquiária, tolerância, planta daninha.

\begin{abstract}
No information is available on selective herbicide to control Brachiaria brizantha cv. Marandu on established pasture of 'Tifton 85'. This work evaluated the selectivity of glyphosate to Tifton 85 culture, using a randomized block design, with eight glyphosate rates (0; 90; 180; 360; 720; 1.080; 1.440 and $\left.1.800 \mathrm{~g} \mathrm{ha}^{-1}\right)$, and four replications. Each plot consisted of a pot with two Brachiaria brizantha $c v$. Marandu plants and two 'Tifton-85' plants. Herbicide was applied when Brachiaria was around $40 \mathrm{~cm}$ high. After 15, 30 and 60 days of application (DAA), intoxication level on Tifton plants and herbicide efficiency on Brachiaria control were evaluated. At 60 DAA, the plants were cut and dried in a greenhouse, and the sprouts evaluated 60 days after cut. Under $738.28 \mathrm{~g} \mathrm{ha}^{-1}$ of glyphosate, $90 \%$ of the Brachiaria brizantha plants were controlled, while Tifton plant intoxication was observed only at $12.05 \%$. At 60 DAA, Brachiaria dry matter production decreased from $90 \mathrm{~g} \mathrm{ha}^{-1}$, with total control of these plants being observed at the rate of $738.28 \mathrm{~g} \mathrm{ha}^{-1}$. Rates higher than $720 \mathrm{~g} \mathrm{ha}^{-1}$ reduced the growth and development of Tifton 85, affecting its production without, however, leading to death of the plants. The results evidenced good selectivity for glyphosate to Tifton 85 culture up to $720 \mathrm{~g} \mathrm{ha}^{-1}$.
\end{abstract}

Keywords: Brachiaria, tolerance, weed.

Recebido para publicação em 23.2.2006 e na forma revisada em 10.11.2006.

Mestranda, Dep. de Fitotecnia, Universidade Federal de Viçosa - DFT/UFV, 36570-000 Viçosa- MG; ${ }^{3}$ Prof. do Dep. de Fitotecnia - DFT/UFV; ${ }^{4}$ Doutor em Fitotecnia - DFT/UFV; ${ }^{5}$ Doutorando, Dep. de Fitotecnia - DFT/UFV; ${ }^{6}$ Prof. do Dep. de Zootecnia - DZO/UFV. 


\section{INTRODUÇÃO}

Atualmente, o uso do gênero Cynodon, também conhecido como gramas bermudas e estrelas, vem se intensificando e se expandindo entre as várias espécies forrageiras, ocupando cada vez mais espaço nas propriedades rurais brasileiras destinadas principalmente à criação de bovinos, eqüídeos e ovinos.

As gramíneas do gênero Cynodon são utilizadas tanto na forma in natura, para pastejo, quanto na forma de forrageira conservada, como silagem e, sobretudo, como feno. Multiplicam-se, principalmente, por meio de mudas enraizadas ou estolões. A exigência em fertilidade do solo varia de média a alta, o que se torna fator limitante no seu estabelecimento (Evangelista et al., 2005). O gênero Cynodon engloba oito espécies, distribuídas em quatro grupos de acordo com sua distribuição geográfica: o primeiro, relacionado à região do sul da Ásia e oceano Índico, abrange as espécies C. arcuatus e C. barberi; o segundo grupo refere-se ao leste da África, contendo as espécies C. plectostachyus, C. aethiopicus e C. nlemfuensis; o terceiro, ao sul da África, é representado por C. incompletus e C. transvaalensis; e o quarto apresenta distribuição cosmopolita, com variedades endêmicas da espécie C. dactylon (Harlan, 1970).

Evangelista (2005) relata que no Brasil a principal ocorrência seria nas regiões Sul, Sudeste e, em menor extensão, no CentroOeste.

Dentre as forrageiras utilizadas para produção de feno e para pastejo, destacam-se os cultivares Coastcross, Tifton 85, Tifton 68 , Florico, Florona e Florakirk (Vileta \& Alvim, 1998; Oliveira et al., 2000; Rovetta et al., 2001; Rosa et al., 2002; Oliveira, 2002). Entre eles, o Tifton 85 merece destaque pela alta produtividade e pelo valor nutritivo, quando comparado com a maioria das bermudas híbridas (Pedreira, 1996), sendo recomendado para fenação e para pastejo em decorrência da boa relação folha/colmo que possui, com boa aceitação por bovinos, eqüídeos, ovinos e caprinos.

O cultivar Tifton 85 foi desenvolvido por Burton et al. (1993) na Coastal Plain Experimente Station, da Universidade da Geórgia, em Tifton, sul do Estado da Georgia.
Essa forrageira é um híbrido F1 entre a introdução Sul-Africana, registro P1 290884 [Cynodon dactylon, e Tifton 68 (Cynodon nlemfuensis).

Em áreas de cultivo de Tifton 85 é comum a ocorrência de outras espécies forrageiras, como Brachiaria brizantha e Brachiaria decumbens, tendo estas uma grande capacidade de interferência, vindo a competir e, em pouco tempo, dominar a pastagem de Tifton 85. Em áreas de criação de eqüinos essa capacidade competitiva é ainda maior, em razão da preferência alimentar desses animais pelo Tifton. Além disso, em áreas de Tifton 85 destinadas à fenação, o gênero Brachiaria é indesejável, devido à redução na qualidade nutricional do feno. Em pastagens de capimelefante e de outras espécies de crescimento cespitoso, ela ocupa os espaços entre as touceiras e concorre com a forrageira principal, reduzindo a qualidade e a quantidade de forragem produzida (Pereira \& Campos, 2001). É também um grande problema na cultura da cana-de-açúcar, bem como em outras culturas, quando se desenvolve nas linhas de plantio ou entre as touceiras. Na cultura do milho, essa espécie chega a provocar quedas de 30 a $80 \%$ da produção (Pereira \& Campos, 2001); em soja, esse índice pode variar de 18 a $82 \%$ (Fleck, 1996).

Acredita-se que a luz, dentre os fatores de produção, é aquele que se destaca na competição da plantas do gênero Brachiaria em relação às plantas de Tifton 85. Isso se deve principalmente à morfologia e ao hábito de crescimento dessas duas espécies forrageiras. Embora ambas sejam espécies com mecanismo de carboxilação do tipo $\mathrm{C}_{4}$ a planta de braquiária possui habito de crescimento ereto (vertical ao solo) e maior porte, formando touceiras e sombreando a planta de Tifton 85, que é uma planta estolonífera com porte menor e crescimento rasteiro (Lorenzi, 2000). Dessa forma, ao serem sombreadas, as plantas de Tifton 85 têm seu potencial de desenvolvimento e crescimento limitado, resultando em menor produtividade.

Assim, é fundamental o controle das plantas do gênero Brachiaria em área de cultivo da forrageira Tifton 85. No entanto, o controle das plantas de braquiária em áreas cujo 
interesse é a exploração de outras gramíneas forrageiras não é uma operação fácil, principalmente pela inexistência no mercado de herbicidas graminicidas seletivos registrados para espécies forrageiras como o Tifton-85 e pelo alto custo operacional dos métodos mecânicos de controle, o que inviabiliza tal operação principalmente em grandes áreas. A persistência da braquiária no solo deve-se, principalmente, ao grande estoque de sementes que fica armazenado no solo e à sua germinação irregular, devido à dormência (Pereira \& Campos, 2001).

O glyphosate [N-(fosfonometil) glicina] é um herbicida sistêmico e não-seletivo, podendo ser formulado na forma de sal de amônio, sal de isopropilamina ou sal potássico e com mecanismo de ação que atua inibindo a enzima EPSPs na rota de síntese dos aminoácidos aromáticos fenilalanina, tirosina e triptofano (Rodrigues \& Almeida, 2005).

A literatura brasileira carece de informações sobre o gênero Cynodon (Vilela \& Alvim, 1998), principalmente quanto ao manejo de plantas daninhas.

Em trabalhos preliminares, observou-se que forrageiras do gênero Brachiaria são mais sensiveis ao herbicida glyphosate que as do gênero Cynodon, portanto, havendo, possibilidade de estabelecimento de doses de glyphosate no controle de $B$. brizantha $\mathrm{cv}$. Marandu, em áreas de pastagem estabelecida de Tifton 85.

Assim, foi proposto este trabalho com o objetivo de avaliar a eficiência do herbicida glyphosate no controle de Brachiaria brizantha cv. Marandu após o estabelecimento de Tifton 85.

\section{MATERIAL E MÉTODOS}

O experimento foi realizado no Campo Experimental Diogo Alves de Mello, pertencente ao Departamento de Fitotecnia da Universidade Federal de Viçosa, entre os meses de dezembro de 2004 e setembro de 2005.

O experimento foi disposto em blocos casualizados com quatro repetições, sendo testadas as doses de 0,0; 90; 180; 360; 720; 1.080; $1.440 ;$ e 1.800 g e.a. ha-1 de glyphosate. Cada parcela foi constituída de um vaso preenchido com $10 \mathrm{~L}$ de solo (LVA), adubado com $436 \mathrm{mg} \mathrm{dm} \mathrm{dm}^{3}$ de superfosfato simples por $\mathrm{m}^{3}$ de solo. O Tifton 85 foi plantado diretamente nos vasos por meio de propagação vegetativa, a partir de mudas extraídas no campo, padronizadas por tamanho (três gemas) e vigor, e $B$. brizantha foi semeada em bandejas a $1 \mathrm{~cm}$ de profundidade, sendo transplantadas para os vasos 20 dias após emergência. Cada vaso continha duas plantas de Tifton 85 intercaladas com duas de $B$. brizantha, sendo colocados em ambiente desprotegido, fora da casa de vegetação. A cada 14 dias, cada vaso foi adubado em cobertura com $3 \mathrm{~g}$ da formulação 20-05-20 (N-P-K) por vaso. Outras espécies daninhas que ocorreram nos vasos foram eliminadas manualmente, a fim de observar o efeito dos tratamentos apenas nas duas espécies forrageiras.

O glyphosate foi aplicado sobre as plantas seis meses após o transplantio das mudas, em ótimas condições ambientais (80\% de umidade relativa do ar, temperatura de $23{ }^{\circ} \mathrm{C}$, velocidade do vento de $4,0 \mathrm{~km} \mathrm{~h}^{-1}$ e solo úmido), utilizando pulverizador costal munido com barra de dois bicos de jato plano ("leque") XR 11002, espaçados entre si de $0,5 \mathrm{~m}$, à pressão constante (mantida pelo $\mathrm{CO}_{2}$ comprimido) de $210 \mathrm{KPa}$, proporcionando volume de calda equivalente a $180 \mathrm{~L} \mathrm{ha}^{-1}$.

A aplicação ocorreu quando as plantas de B. brizantha apresentavam cerca de $40 \mathrm{~cm}$ de altura e 10 perfilhos, simulando condições de plantas em área de pastagem já estabelecida (Figura 1). O produto comercial utilizado foi o Roundup Original CS, na concentração de 360 g e.a. $\mathrm{L}^{-1}$ de glyphosate.

Foram realizadas avaliações de controle das plantas de $B$. brizantha aos 15, 30 e 60 dias após aplicação do herbicida (DAA), por meio de observações visuais, utilizando-se escala de 0 a 100, sendo 0 ausência de controle e 100 controle total da espécie. O nível de intoxicação das plantas de Tifton 85 foi também avaliado aos 15, 30 e 60 DAA, utilizando a escala de 0 a 100, em que 0 é ausência de intoxicação e 100 morte das plantas (Frans, 1972).

Aos 60 DAA, ambas as espécies foram colhidas ao nivel do solo e secas em estufa de ventilação forçada de ar a $70 \mathrm{r}\left[\mathrm{B}^{\circ} \mathrm{C}\right.$, até peso constante. Após o corte das plantas, os solos 


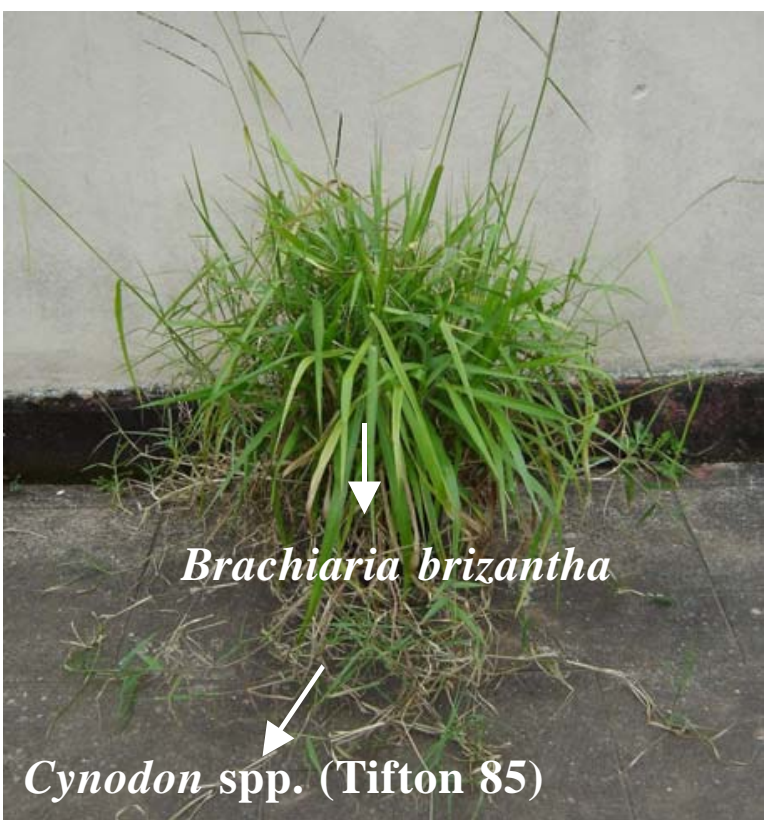

Figura 1 - Estádios de desenvolvimento de Tifton 85 (Cynodon spp.) e Brachiaria brizantha cv. Marandu, no momento da aplicação do glyphosate.

dos vasos foram devidamente adubados e irrigados para avaliar a capacidade de rebrota das plantas aos 60 dias após o corte (DAC).

Com base na massa seca e na análise visual das plantas, foi determinada qual a melhor dose para controle de B. brizantha cv. Marandu, quando cultivado conjuntamente com Tifton 85, nas diferentes épocas analisadas.

Os resultados obtidos foram submetidos às análises de variância pelo teste $\mathrm{F}$ a $5 \%$ de probabilidade. Foram ajustadas equações de regressão em função das doses aplicadas, para os dados de controle de B. Brizantha cv. Marandu e intoxicação de Tifton 85, e teste de comparação de médias, para os dados de massa seca de ambas as espécies estudadas, por meio do teste de Duncan (5\%).

\section{RESULTADOS E DISCUSSÃO}

A eficiência do herbicida no controle de plantas de $B$. brizantha cv. Marandu foi influenciada pela dose utilizada $(\mathrm{P}<0,05)$. Controle máximo de $85,27 \%$ de $B$. brizantha foi observado aos 15 dias após a aplicação (DAA) na dose equivalente a $1.800 \mathrm{~g} \mathrm{ha}^{-1} \mathrm{de}$ glyphosate, e superior a $90 \%$ aos 30 DAA a partir da dose de 892,97 $\mathrm{g} \mathrm{ha}^{-1}$. Aos 60 DAA, observou-se controle superior a $90 \%$ a partir da dose de 738,28 $\mathrm{g} \mathrm{ha}^{-1}$ de glyphosate (Figura 2).

Os sintomas de intoxicação do Tifton 85 intensificaram-se com o aumento da dose utilizada, nas diferentes épocas avaliadas $(\mathrm{P}<0,05)$. Os sintomas foram semelhantes aos descritos por Roman et al. (2004) quando da utilização de glyphosate na dessecação de $B$. plantaginea, sendo típicos de produtos cujo mecanismo de ação ocorre na inibição da síntese de aminoácidos e cuja intensidade varia em função da dose utilizada.

Nas doses menores que $720 \mathrm{~g} \mathrm{ha}^{-1}$, as plantas de Tifton 85 apresentaram sintomas visíveis mais tardiamente (após 15 DAA) e em menor intensidade, sendo caracterizados por leve clorose das folhas, brotações de gemas laterais e redução de crescimento. No entanto, para doses superiores a $720 \mathrm{~g} \mathrm{ha}^{-1}$, os sintomas foram mais precoces e intensos, com grande clorose das folhas, seguido de necrose, alta redução de crescimento.

Aos 15 DAA, intoxicação máxima de 29,8\% das plantas de Tifton 85 foi observada para a dose equivalente a $1.800 \mathrm{~g} \mathrm{ha}^{-1}$ de glyphosate. Aos 30 e 60 DAA, os valores máximos de intoxicação - 51,8 e $44,9 \%$, respectivamente também foram observados nas plantas tratadas com $1.800 \mathrm{~g} \mathrm{ha}^{-1}$ de glyphosate (Figura 3).

As porcentagens de intoxicação das plantas de Tifton 85 , em relação às doses de controle de $B$. brizantha aos 60 DAA, foram relativamente baixas, atingindo 25,28 e $12,05 \%$ de intoxicação nas doses equivalentes a 892,97 e 738,28 $\mathrm{g} \mathrm{ha}^{-1}$ de glyphosate, respectivamente. Isso evidencia a maior tolerância das plantas de Tifton 85 ao glyphosate, em comparação a $B$. brizantha (Figuras 2 e 3), demonstrando seu potencial de uso em pastagens após o estabelecimento.

A produção de massa seca variou entre as diferentes doses testadas $(\mathrm{p}<0,05)$, aos 60 DAA e 60 DAC (Tabela 1). Aos 60 DAA, observou-se menor produção de massa seca de $B$. brizantha com o aumentoi das doses aplicadas do herbicida e morte das plantas a partir da dose de $720 \mathrm{~g} \mathrm{ha}^{-1}$ de glyphosate (Figura 4).

O Tifton 85 apresentou, aos 60 DAA, acréscimo na produção, alcançando um máximo na 
dose equivalente a $360 \mathrm{~g} \mathrm{ha}^{-1}$ de glyphosate, com posterior decréscimo a partir dessa dose. O aumento da massa seca produzida, para esta espécie, em relação à testemunha, pode ser atribuído a redução da competição de $B$. brizantha, que foi mais sensivel ao glyphosate. Por sua vez, a queda na produção a partir da dose equivalente a $720 \mathrm{~g} \mathrm{ha}^{-1} \mathrm{de}$ glyphosate está relacionada à menor tolerância das plantas de Tifton 85 a doses mais elevadas do herbicida, causando diminuição no crescimento e desenvolvimento desta forrageira, afetando sua produção, sem, no entanto, ocasionar a morte das plantas (Figura 4).

Analisando a Figura 5, referente à massa seca da rebrota, colhida aos 60 DAC, observou-se redução na produção de $B$. brizantha em plantas tratadas com doses superiores a $180 \mathrm{~g} \mathrm{ha}^{-1}$ de glyphosate e ausência de rebrota a partir da dose de $720 \mathrm{~g} \mathrm{ha}^{-1}$ de glyphosate.

Em relação à rebrota das plantas de Tifton 85, aos 60 DAC, observou-se produção crescente de massa seca até $360 \mathrm{~g} \mathrm{ha}^{-1} \mathrm{de}$

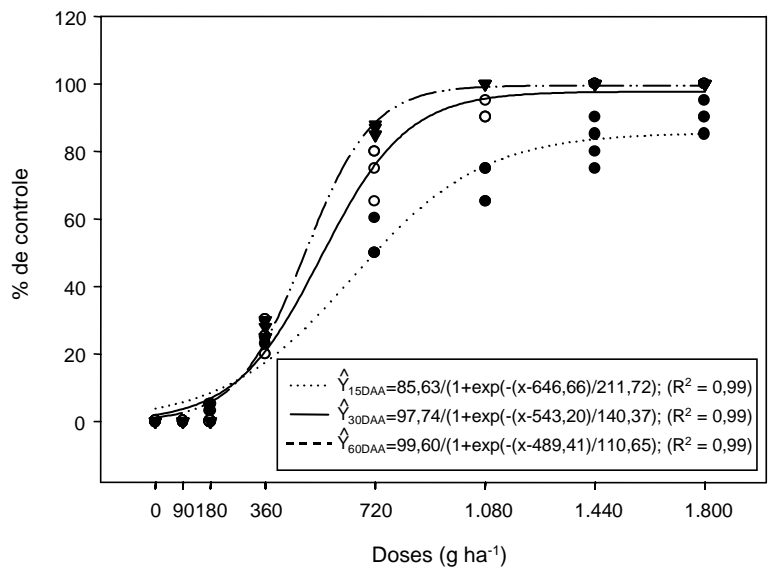

Figura 2 - Porcentagem de controle de Brachiaria brizantha cv Marandu aos 15, 30 e 60 dias após a aplicação (DAA), em função das doses de $0,90,180,360 ; 720,1.080,1.440$ e 1.800 g e.a. ha- ${ }^{-1}$ de glyphosate.

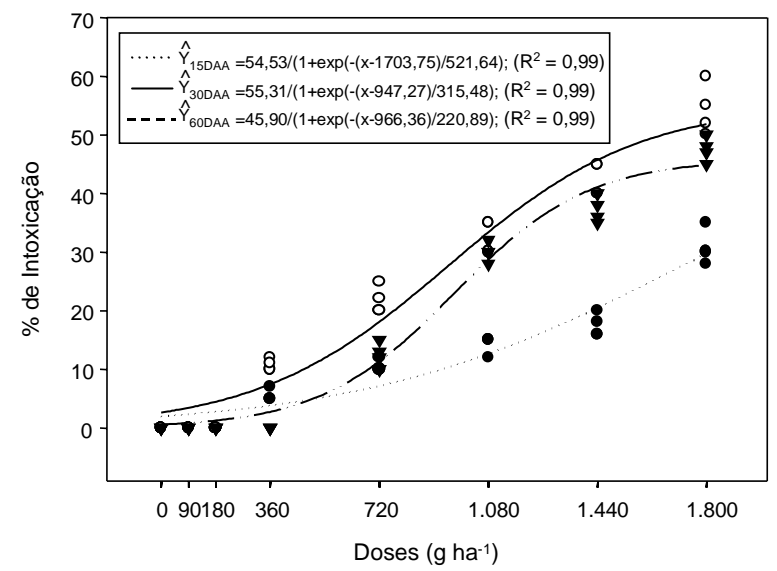

Figura 3 - Porcentagem de intoxicação das plantas de Tifton 85 (Cynodon spp.) aos 15, 30 e 60 dias após a aplicação (DAA), em função das doses de 0, 90, 180, 360, 720, 1.080, 1.440 e 1.800 g e.a. ha- ${ }^{-1}$ de glyphosate.

Tabela 1 - Massa seca de plantas de Tifton 85 (Cynodon spp.) e Brachiaria brizantha cv. Marandu, submetidas às doses de 0,90, 180, 720, 1.080, 1.440 e 1.800 g e.a. ha $^{-1}$ do glyphosate, aos 60 dias após aplicação (DAA) e na rebrota, aos 60 dias após o corte (DAC)

\begin{tabular}{|c|c|c|c|c|}
\hline \multirow{3}{*}{$\begin{array}{l}\text { Glyphosate } \\
\text { Dose }\left(\mathrm{g} \mathrm{ha}^{-1}\right)\end{array}$} & \multicolumn{2}{|c|}{$60 \mathrm{DAA}$} & \multicolumn{2}{|c|}{$60 \mathrm{DAC}$} \\
\hline & Tifton 85 & Brachiaria brizantha & Tifton 85 & Brachiaria brizantha \\
\hline & \multicolumn{4}{|c|}{ Matéria Seca (g por vaso) } \\
\hline Testemunha & $163,37 \mathrm{~b}$ & $207,71 \mathrm{a}$ & $27,16 \mathrm{c}$ & $29,35 \mathrm{~b}$ \\
\hline 90 & $119,81 \mathrm{c}$ & $153,61 \mathrm{~b}$ & $19,84 \mathrm{~d}$ & $37,34 \mathrm{a}$ \\
\hline 180 & $153,16 \mathrm{~b}$ & $146,53 \mathrm{~b}$ & $37,20 \mathrm{~b}$ & $15,40 \mathrm{c}$ \\
\hline 360 & $183,47 \mathrm{a}$ & $47,31 \mathrm{c}$ & $54,43 \mathrm{a}$ & $4,53 \mathrm{~d}$ \\
\hline 720 & $100,51 \mathrm{~d}$ & $0,0 \mathrm{~d}$ & $30,98 \mathrm{bc}$ & $0,0 \mathrm{~d}$ \\
\hline 1.080 & $59,05 \mathrm{e}$ & $0,0 \mathrm{~d}$ & $31,25 \mathrm{bc}$ & $0,0 \mathrm{~d}$ \\
\hline 1.440 & $33,64 \mathrm{f}$ & $0,0 \mathrm{~d}$ & $8,81 \mathrm{e}$ & $0,0 \mathrm{~d}$ \\
\hline 1.800 & $28,81 \mathrm{f}$ & $0,0 \mathrm{~d}$ & $5,85 \mathrm{e}$ & $0,0 \mathrm{~d}$ \\
\hline $\mathrm{CV}(\%)$ & 12,05 & 22,79 & 18,12 & 28,09 \\
\hline
\end{tabular}

Médias seguidas pelas mesmas letras na coluna não diferem entre si pelo teste de Duncan a 5\% de probabilidade. 
glyphosate, devido a eliminação da competição de $B$. brizantha, decrescendo em plantas expostas a doses superiores a essa. O decréscimo da produção de massa seca pode ser atribuído ao efeito direto do glyphosate sobre o Tifton 85, uma vez que nessas doses a $B$. brizantha foi totalmente controlada (Figura 5).

Silva et al. (2006) recomendam a adubação da forrageira após o controle químico de invasoras em pastagem e retirada dos animais da área favorecendo o desenvolvimento e restabelecimento da forrageira, integrando

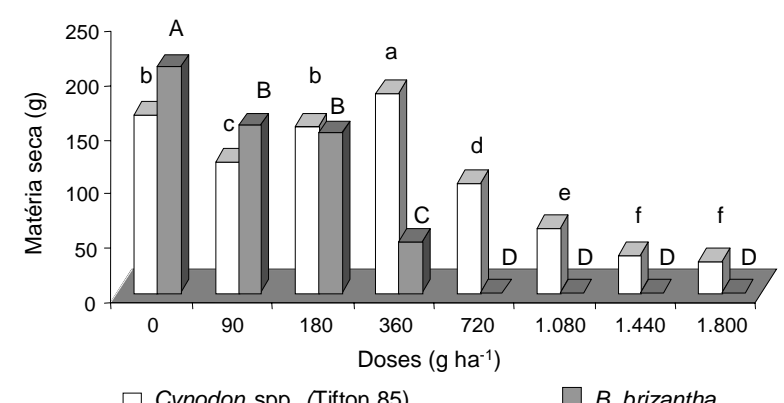

Médias seguidas pela mesma letra não diferem entre si pelo teste de Duncan a $5 \%$ de probabilidade, sendo letras maiúsculas referentes a Brachiaria brizantha e minúsculas ao Tifton 85 .

Figura 4 - Massa seca de Tifton 85 (Cynodon spp.) e Brachiaria brizantha $\mathrm{cv}$. Marandu aos 60 dias após a aplicação (DAA), em função das doses de 0, 90, 180, 360, 720, 1.080, $1.440 \mathrm{e}$ 1.800 g e.a. ha ${ }^{-1}$ de glyphosate.

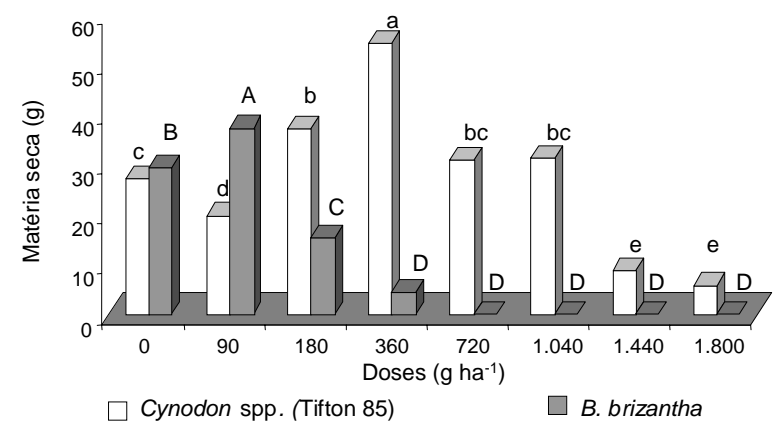

Médias seguidas pela mesma letra não diferem entre si pelo teste de Duncan a $5 \%$ de probabilidade, sendo letras maiúsculas referentes a Brachiaria brizantha e minúsculas a Tifton 85 .

Figura 5 - Massa seca da rebrota de Tifton 85 (Cynodon spp.) e Brachiaria brizantha cv. Marandu aos 60 dias após o corte (DAC), em função das doses de 0, 90, 180, 360, 720, 1.080, 1.440 e $1.800 \mathrm{~g}$ e.a. ha-1 de glyphosate. assim o manejo cultural ao químico. Dessa forma, tal prática deve ser adotada no caso do uso do glyphosate para controle de $B$. brizantha em áreas de Tifton 85, visando a recuperação dessa forrageira.

Os resultados evidenciaram a eficiência do glyphosate no controle de $B$. brizantha cv. Marandu em pastagem de Tifton 85 após o estabelecimento.

\section{LITERATURA CITADA}

BURTON, G. W.; GATES, R. N.; HILL, G. M. Registration of 'Tifton 85 ' bermudagrass. Crop Sci., v. 33, n. 3 , p. $644-645,1993$

EVANGELISTA, A R.; REZENDE, A. V.; AMARAL, P. N. C Produção de feno de gramíneas. In: FORRAGICULTURA E PASTAGENS TEMAS EM EVIDÊNCIA, 2005, Lavras. Anais... Lavras: Universidade Federal de Lavras, 2005. p. $247-276$

FRANS, R. E. Measuring plant responses. In: WILKINSON, R. E. (Ed.). Research methods in weed science. Atlanta: Southern Weed Science Society, 1972. p. 27-41.

FLECK, N. G. Interferência de papuã (Brachiaria plantaginea) com soja e ganho de produtividade obtido através do seu controle. Pesq. Agropec. Gaúcha, v. 2, n. 1, p. 63-68, 1996.

HARLAN, J. R. Gênero Cynodon. Review article. In: Herbage Abstracts., v. 40, n. 3, p. 233-238, 1970.

LORENZI, H. Manual de identificação e controle de plantas daninhas. 5.ed. Nova Odessa-SP: Instituto Plantarum, 2000. $339 \mathrm{p}$

OLIVEIRA, M. A. et al. Rendimento e valor nutritivo do capim-tifton 85 (Cynodon spp.) em diferentes idades de rebrota. Rev. Bras. Zootec., v. 29, n. 6, p. 1949-1960, 2000.

OLIVEIRA, M. A. Características morfofisiológicas e valor nutritivo de gramíneas forrageiras do gênero Cynodon sob diferentes condições de irrigação, fotoperíodo, adubação nitrogenada e idade de rebrota 2002. 142 f. Tese (Doutorado em Zootecnia) - Universidade Federal de Viçosa, Viçosa, MG, 2002.

PEDREIRA, C. G. S. Avaliação de novas gramíneas do gênero Cynodon para a pecuária do sudeste dos Estados Unidos. In: WORKSHOP SOBRE O POTENCIAL FORRAGEIRO DO GÊNERO CYNODON, 1996, Juiz de Fora. Anais... Juiz de Fora: EMBRAPA-CNPGL, 1996. p. 111-125. 
PEREIRA, J. R.; CAMPOS, A. T. Controle da braquiária como invasora. Instrução técnica para o produtor de leite. Juiz de Fora: Embrapa Gado de Leite, 2001.

RODRIGUES, B. N.; ALMEIDA, F. S. Guia de herbicidas. 3.ed. Londrina: IAPAR, 2005. $591 \mathrm{p}$.

ROMAN, E. S. et al. Influência do orvalho e volume de calda de aplicação na eficácia do glyphosate na dessecação de Brachiaria plantaginea. Planta Daninha, v. 22, n. 3, p. 479482, 2004.

ROSA, B. et al. Valor nutritivo dos fenos de soja perene e do capim tifton 85 adubado com diferentes doses de nitrogênio. In: REUNIÃO ANUAL DA SOCIEDADE BRASILEIRA DE ZOOTECNIA, 2002, Recife. Anais... Recife: UFRPE, 2002. CD-ROM.
ROVETTA, R. et al. Morfogênese foliar do capim-bermuda 'Tifton 85 ' sob diferentes doses de nitrogênio, colhido ao atingir 30, 40 e $50 \mathrm{~cm}$ de altura. In: REUNIÃO ANUAL DA SOCIEDADE BRASILEIRA DE ZOOTECNIA, 2001, Piracicaba. Anais... Piracicaba: Escola Superior de Agricultura "Luiz de Queiroz", 2001. p.167-169.

SILVA, A. A. et al. Biologia e controle de plantas daninhas. Viçosa, MG: DFT/UFV, 2006. CD-ROM.

VILELA, D.; ALVIM, M. M. Manejo de pastagem do gênero Cynodon: introdução, caracterização e evolução do uso no Brasil. In: SIMPOSIO SOBRE MANEJO DE PASTAGEM: manejo de pastagens de tifton, coastcross e estrela, 15., 1998, Piracicaba. Anais... Piracicaba: Fundação de Estudos Agrários "Luiz de Queiroz", 1998. p. 23-54. 